\title{
The mechanisms of conventional pollutants adsorption by modified granular steel slag
}

\author{
Shaona Wang ${ }^{1}$, Sijian Yao ${ }^{1}$, Kang Du ${ }^{2}$, Rongfang Yuan ${ }^{{ }^{+}}$, Huilun Chen ${ }^{1}$, Fei Wang', Beihai Zhou ${ }^{1^{+}}$ \\ ${ }^{1}$ Beijing Key Laboratory of Resource-oriented Treatment of Industrial Pollutants, Department of Environmental Science and Engineering, School of \\ Energy and Environmental Engineering, University of Science and Technology Beijing, Beijing 100083, China \\ ${ }^{2}$ Beijing Municipal Research Institute of Environmental Protection, Beijing, 100037, China
}

\begin{abstract}
This study was performed to investigate the removal of phosphorus, nitrogen, ammonia and dissolved organic matter (DOM) from domestic wastewater using modified granular steel slag (GSS) as adsorbent. The modification methods include acid modification, alkalinity modification and thermal modification. The GSS modified at $800^{\circ} \mathrm{C}$ for $1 \mathrm{~h}$ was easier to hydrolyze $\mathrm{Ca}^{2+}$, which could promote the precipitation of phosphates and the ion exchange process of ammonia. Therefore, the adsorptive capacity of GSS for phosphates and ammonia could be significantly improved by the thermal treatment. The acid-modified GSS promoted the adsorption capacity of nitrates by increasing surface protonation, specific surface area and pore size. The highest nitrates adsorption capacity was obtained when GSS was immersed in $1 \mathrm{~mol} / \mathrm{L} \mathrm{HCl}$ solution for $24 \mathrm{~h}$. The presence of nitrates inhibited the adsorption of phosphates by GSS because the adsorption of nitrates and phosphates by GSS depended largely on electrostatic attraction and intermolecular force, and the competition between them reduced the adsorption capacity. Ammonia can promote the hydrolysis of metal ions on the surface of GSS, increase the concentration of metal ions in solution and promote the formation of phosphate precipitation, but ammonia also competed with phosphate for active sites on the surface of GSS. The effect of ammonia nitrogen on phosphate adsorption was the result of the interaction of the two mechanisms. For domestic wastewater, the thermally modified GSS showed the best adsorption rate of total phosphorus and total nitrogen, and the acid-modified GSS had better adsorption capacity for organic matter. The thermally modified GSS had a good application effect in laboratory subsurface flow constructed wetlands.
\end{abstract}

Keywords: Acid modification, Adsorption, Granular steel slag, Nitrogen, Phosphorus, Thermal modification

\section{Introduction}

With the increasingly stringent discharge standards of sewage treatment, the biological treatment process such as activated sludge treatment and sequencing batch reactors cannot meet the discharge requirements of sewage [1]. Therefore, the biological treatment process needs to be combined with the follow-up treatment process such as constructed wetlands, deep filtration, coagulation and adsorption to realize the sewage discharge standard [2-5]. Among these processes, adsorption has been widely used because of its simple operation, stable function, and adsorbent can be recycled to avoid sludge production [6-8]. In recent years, researches on adsorbents have been carried out [5, 9-13]. As a by-product of the steel industry, steel slag could adsorb the pollutants because of the pits, holes and different functional groups on its surface [14].
Slag mainly composed of $\mathrm{CaO}, \mathrm{Al}_{2} \mathrm{O}_{3}, \mathrm{Fe}_{2} \mathrm{O}_{3}, \mathrm{MgO}$ and $\mathrm{SiO}_{2}$, which makes it capable of removing contaminants through the formation of insoluble salts. Most of the studies focused on the adsorption capacity of modified steel slag for heavy metals, many heavy metal ions such as $\mathrm{Cu}, \mathrm{Zn}, \mathrm{Pb}, \mathrm{Ni}$ and $\mathrm{Cr}$ can be adsorbed by steel slag through the replacement of $\mathrm{Ca}^{2+}[15,16]$. Based on these theoretical studies, the adsorption capacity of steel slag was applied to the treatment of conventional pollutants, and great results had been achieved. Steel slag composed of calcium-rich oxides and silicates can be used for phosphorus removal and recovery from wastewater, because steel slag can provide sufficient $\mathrm{Ca}^{2+}$ and $\mathrm{OH}^{-}$for the formation of calcium phosphate $\left(\mathrm{Ca}-\mathrm{PO}_{4}\right)$ precipitates [17]. The removal efficiencies of ammonia nitrogen and total phosphorus could be improved apparently when the mass concentration of steel of 2.2-2.4 g/L were applied [18].
This is an Open Access article distributed under the terms of the Creative Commons Attribution Non-Commercial License (http://creativecommons.org/licenses/by-nc/3.0/) which permits unrestricted non-commercial use, distribution, and reproduction in any medium, provided the original work is properly cited.

Copyright (C) 2021 Korean Society of Environmental Engineers
Received August 21, 2019 Accepted January 26, 2020

${ }^{\dagger}$ Corresponding author

Email: zhoubeihai@sina.com, yuanrongfang@ustb.edu.cn Tel: : +86-10-62334821, +86-62334821 Fax: +86-10-62334821, +86-62334821 ORCID: 0000-0001-6137-395X 
However the adsorption ability of steel slag was limited because of its poor pore structure and small specific surface area [6], in order to improve the adsorptive capacity of steel slag, the modification methods include thermal modification, high temperature calcination with other materials, reaction with acid or alkali solution and mechanical grinding were studied [19-22]. The removal efficiency of phosphorus by thermal modified steel slag was increased because the surface of the modified slag was cracked and that the texture became loose after heating [23]. In addition, the nitrate adsorption capacity of the steel slag modified at $800^{\circ} \mathrm{C}$ approximately increased by 0.9 times [24]. Most of the research focused on thermal modification and phosphorus removal effect of modified steel slag, while less on the adsorption capacity of conventional pollutants such as organic matters, nitrates and ammonia in wastewater. There are few studies on the effect of steel slag removal of pollutants after different modification methods, and the physical and chemical properties of steel slag modified by various methods need further comparative analysis.

In this study, the acid treatment, alkali treatment, and high-temperature heating were used to modify the granular steel slag (GSS). The optimum modification conditions were determined by the adsorption experiments of phosphates, nitrates and ammonia. The surface structure of the modified GSS was analyzed through characterization method including the X-ray diffraction (XRD), scanning electron microscopy (SEM) and $\mathrm{N}_{2}$ adsorption-desorption analyses. The mechanisms of the adsorption for phosphates, nitrates and ammonia by GSS were explored by measuring the changes of $\mathrm{pH}$ value, the concentration of $\mathrm{Ca}^{2+}$ hydrolyzed from GSS during the adsorption process and the amount of phosphates removed by precipitation. In addition, the removal effect of modified GSS on pollutants in subsurface flow constructed wetland (SFCW) was investigated.

\section{Material and Methods}

\subsection{Materials}

The GSS with the particle size of 1-2 mm was obtained from a steelmaking plant in Zhengzhou, China. GSS was washed five times with the deionized water and dried before the experiment. The proportional mass composition of the GSS was $\mathrm{Fe}_{2} \mathrm{O}_{3} 36.22 \%$, $\mathrm{SiO}_{2} 27.87 \%, \mathrm{CaO} 15.17 \%, \mathrm{Al}_{2} \mathrm{O}_{3} 6.3 \%$. The concentration of $\mathrm{HCl}$ and $\mathrm{NaOH}$ solution used in GSS modification was 1-5 mol/L. All the chemicals in the experiment were of analytical grade.

\subsection{Modification Methods}

For the acid or alkaline modification, $10 \mathrm{~g}$ of GSS was immersed in $100 \mathrm{~mL} \mathrm{NaOH}$ or $\mathrm{HCl}$ for $24 \mathrm{~h}$. For thermal modification, the GSS was heated directly at $600-1000^{\circ} \mathrm{C}$ for $1 \mathrm{~h}$ in a muffle furnace. All the modified GSS was washed five times with deionized water and dried before use.

The main chemical constituents of the samples were measured by the X-ray fluorescence spectrometer (XRF-1800, Shimadzu, Japan). The surface structure of GSS was obtained by XRD (MXP21VAHF, MACSCIENCECO, Japan) and SEM (LEO1450, LEO, America). The specific surface areas of the samples were calculated from the $\mathrm{N}_{2}$ sorption isotherms at $196^{\circ} \mathrm{C}$ by the Brunauer, Emmett and Teller (BET) method, and the pore size distribution of samples was determined by the Bearrett-Joyner-Halenda (BJH) method with an ASAP2020 device (Micromeritics, Norcross, GA, USA).

\subsection{Batch Adsorption Experiments and Subsurface Flow Constructed Wetland Continuous Experiment}

The adsorption experiments of modified GSS were carried out with artificial water and domestic wastewater. The GSS (1 g) was placed in a $150 \mathrm{~mL}$ plugged conical flask, and the $100 \mathrm{~mL}$ preparation solution was added. It was shaken in a constant temperature shaker at $25^{\circ} \mathrm{C}$ and $200 \mathrm{r} / \mathrm{min}$ for $24 \mathrm{~h}$. The centrifugal separation was carried out and the supernatant was taken to determine the concentration of residual pollutants. The adsorption capacity of the pollutants was calculated by the Eq. (1).

$$
q_{\mathrm{e}}=\left[\left(C_{0}-C_{\mathrm{e}}\right) \times V\right] / m
$$

where $q_{e}$ is the adsorption amount of GSS for each pollutant at $24 \mathrm{~h}$; $C_{0}$ is the initial concentration of pollutant; $C_{\mathrm{e}}$ is the residual concentration of pollutant after $24 \mathrm{~h}$; $V$ is the volume of pollutant; $m$ is the mass of adsorbent.

The inlet water of the SFCW was the outlet water of the $\mathrm{A} / \mathrm{O}$ contact oxidation tank in the laboratory. The schematic diagram was shown in Fig. S1. In the experiment, three kinds of SFCW were designed, Experience group 1 (G1) was filled with thermally modified GSS and planted reed, G2 was filled with unmodified GSS and planted reed, G3 was filled with thermally modified GSS but no reed. The HRT of SFCW was $48 \mathrm{~h}$.

\subsection{Test Method}

The concentration of chemical oxygen demand $\left(\mathrm{COD}_{\mathrm{Cr}}\right)$, total nitrogen (TN), nitrates, ammonia, total phosphorus (TP) and phosphates was measured according to the Chinese National Standard Methods [25]. The morphology of phosphorus in the GSS after adsorption was determined by the soil chemical analysis [19]. All the above experiments were performed using an ultraviolet spectrophotometer (760CRT, Prismatic, China) in triplicate and the data were expressed using the average values. The molecular weight change of the organic matter in domestic wastewater was determined by high-performance size-exclusion chromatography using a Waters 2690 separation module and 996 photodiode array detector (Waters, America) [26]. The concentration of the metal ions hydrolyzed by the GSS in the solution was measured using the Inductively Coupled Plasma Optical Emission Spectrometer (Optima8300, PerkinElmer, America), and the $\mathrm{pH}$ change of the solution was measured by a $\mathrm{pH}$ meter (HQ11D, HACH, America).

\section{Results and Discussion}

\subsection{Characterization of Adsorbents}

\subsubsection{Components and XRD analysis}

The main components of the original GSS and modified GSS were shown in Table S2, the results indicated that the composition of GSS had changed after modification. The composition of iron oxide and calcium oxide in GSS decreased, while the composition of silicon dioxide increased. In the process of modification, the 


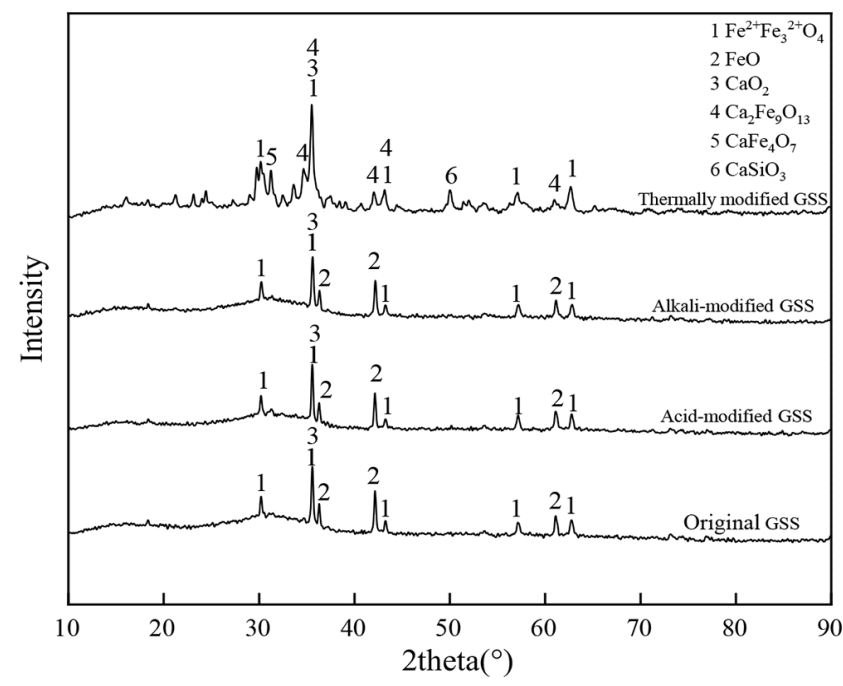

Fig. 1. XRD spectra of GSS.

surface properties of GSS were changed firstly. The change of surface components of GSS would affect the surface polarity of GSS, and affect the adsorption capacity of GSS.

The XRD spectrums showed that the peaks were complex and overlapping (Fig. 1). The original GSS, acid-modified GSS and alkali-modified GSS had almost same diffraction peaks. Their main mineral phases were $\mathrm{Fe}^{2+} \mathrm{Fe}_{3}{ }^{2+} \mathrm{O}_{4}, \mathrm{FeO}$ and $\mathrm{CaO}_{2}$. After thermal modification, the $\mathrm{FeO}$ peaks in GSS disappeared and some new diffraction peaks were produced. These peaks were $\mathrm{Ca}_{2} \mathrm{Fe}_{9} \mathrm{O}_{13}$, $\mathrm{CaFe}_{4} \mathrm{O}_{7}$, and $\mathrm{CaSiO}_{3}$, which formed by the reaction of $\mathrm{CaO}$ with
$\mathrm{FeO}$ and $\mathrm{SiO}_{2}$ respectively, $\mathrm{CaO}$ was decomposed from $\mathrm{CaO}_{2}$ at high temperature. $\mathrm{Ca}_{2} \mathrm{Fe}_{9} \mathrm{O}_{13}, \mathrm{CaFe}_{4} \mathrm{O}_{7}$, and $\mathrm{CaSiO}_{3}$ on the surface of GSS were easier to release $\mathrm{Ca}^{2+}$, which was beneficial to the precipitation in the reaction with phosphates, and improved the chemical adsorption capacity of GSS. The formation of Ca-P was largely depended on the dissolution of $\mathrm{CaSiO}_{3}$ from GSS [27]. The width and strength of the peak of thermal modification also changed in various degrees, indicating that the high-temperature calcination changed the crystallinity of GSS.

\subsubsection{BET and SEM analysis}

The changes of surface morphology, specific surface area and pore size distribution after GSS modification can be seen from Fig. 2 and Fig. S1. The surface of the original GSS was relatively smooth, with the specific surface area of $0.47 \mathrm{~m}^{2} / \mathrm{g}$ and the pore volume of 0.00024 $\mathrm{m}^{3} / \mathrm{g}$. After acid modification, a large number of pores (diameter 2-8 $\mathrm{nm}$ ) appeared on the surface of GSS. The increased specific surface area of GSS was $1.33 \mathrm{~m}^{2} / \mathrm{g}$, which provided a large number of active sites for the adsorption of the pollutants. The GSS after calcination at $800^{\circ} \mathrm{C}$ became soft and easier to hydrolyze metal ions. However, the thermal modification caused huge cracks on the surface of GSS, and even led to the collapse of GSS holes. Therefore, no hole could be seen on the surface of GSS after thermal modification. The specific surface area and pore volume decreased obviously, which was only $1 / 20$ of the original GSS. Alkali liquid had good pore-enlarging effect on GSS, and the cumulative pore area of the alkali-modified GSS was $0.57 \mathrm{~m}^{2} / \mathrm{g}$, alkali-modified GSS had a large pore diameter and a pore size distribution of 2-120 $\mathrm{nm}$. A large amount of precipitation was observed on the surface of GSS by SEM, they were products of the reaction of $\mathrm{NaOH}$ with metal oxides on the surface of GSS.

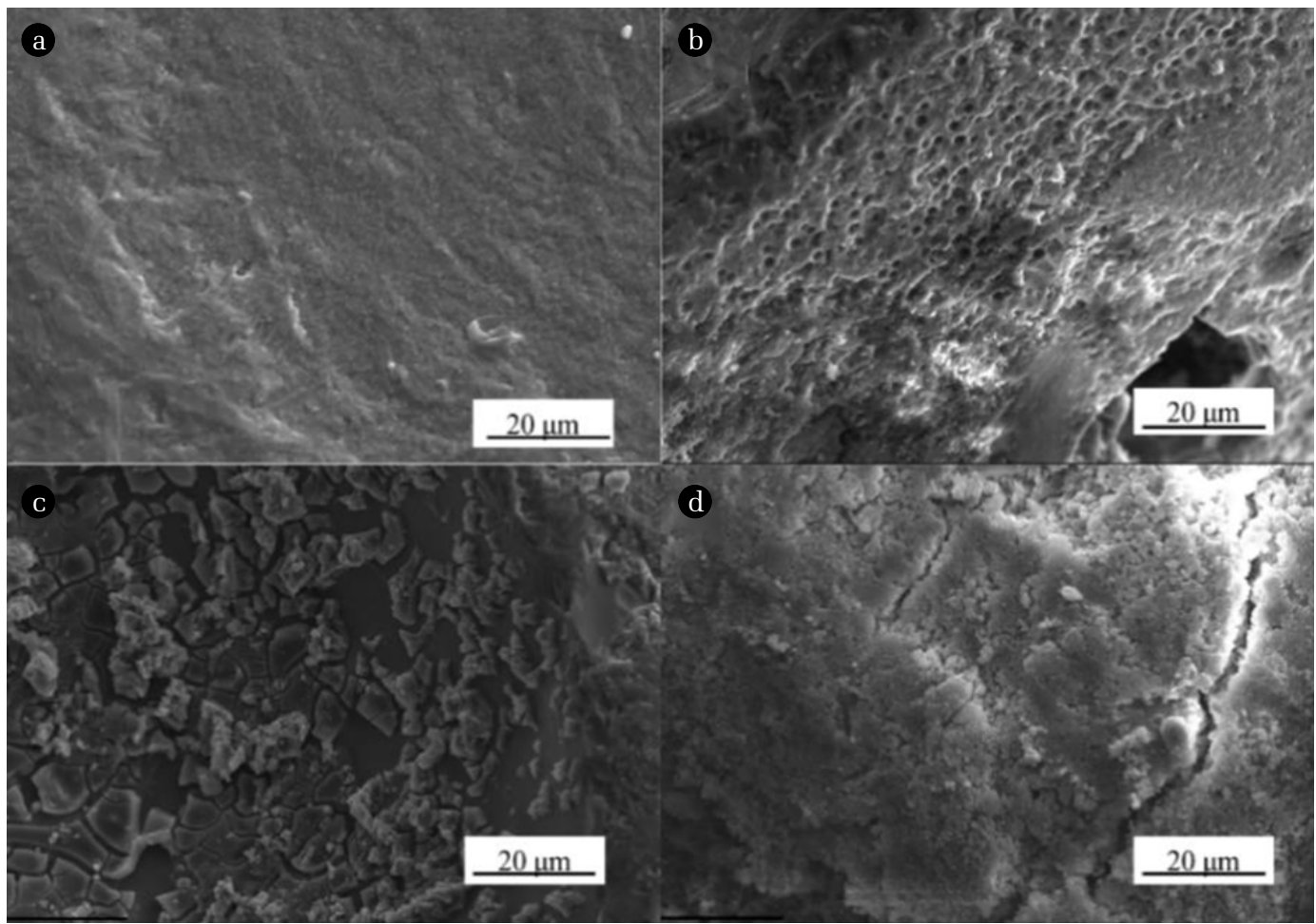

Fig. 2. SEM photographs: (a) Original GSS; (b) Acid-modified GSS; (c) Alkali-modified GSS; (d) Thermally modified GSS. 

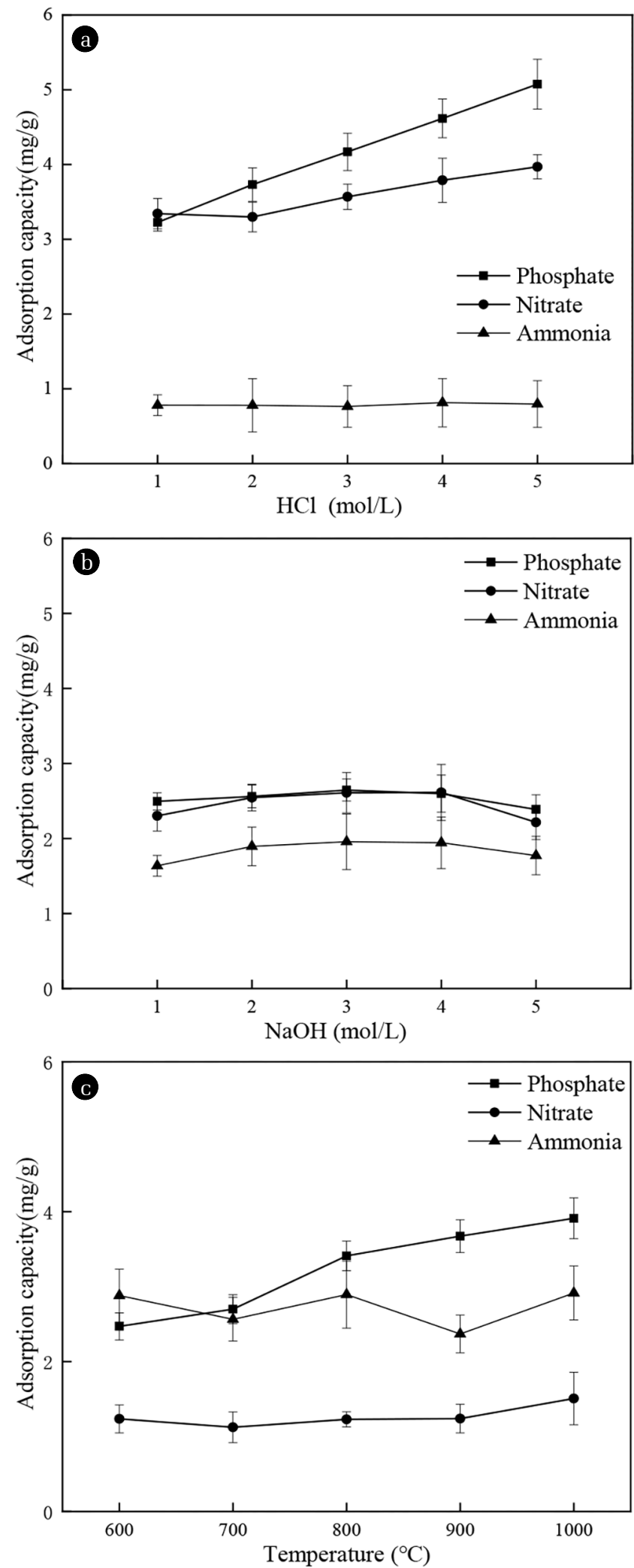

Fig. 3. Adsorption capacity of GSS to various pollutants (a) Acid modification; (b) Alkali modification; (c) Thermal modification.

\subsection{Adsorption Effect and Mechanisms of Conventional Pollutants}

\subsubsection{Adsorption effect and mechanisms of phosphates}

The adsorption capacity of the modified GSS for phosphates was shown in Fig. 3. The original GSS had a phosphates adsorption capacity of $2.33 \mathrm{mg} / \mathrm{g}$, and the main mechanisms of phosphates removal by GSS were chemical precipitation and ligand exchange $[14,22,28]$. The main mechanism of chemical precipitation was that $\mathrm{Ca}^{2+}, \mathrm{Fe}^{2+}, \mathrm{Al}^{3+}$ hydrolyzed from GSS reacted with phosphates to form Ca-P and other precipitations [27, 29-31]. The main equations are as follows:

$$
\begin{aligned}
& \mathrm{Ca}^{2+}+2 \mathrm{H}_{2} \mathrm{PO}_{4}^{-}+\mathrm{H}_{2} \mathrm{O} \rightarrow \mathrm{Ca}\left(\mathrm{H}_{2} \mathrm{PO}_{4}\right)_{2} \cdot \mathrm{H}_{2} \mathrm{O} \\
& \mathrm{Ca}\left(\mathrm{H}_{2} \mathrm{PO}_{4}\right)_{2}+2 \mathrm{Ca}^{2+} \rightarrow 2 \mathrm{CaHPIO}_{4}+2 \mathrm{H}^{+} \\
& 6 \mathrm{CaHPO}_{4}+2 \mathrm{Ca}^{2+} \rightarrow \mathrm{Ca}_{8} \mathrm{H}_{2}\left(\mathrm{PO}_{4}\right)_{6}+26 \mathrm{H}^{+} \\
& \mathrm{Ca}_{8} \mathrm{H}_{2}\left(\mathrm{PO}_{4}\right)_{6}+2 \mathrm{Ca}^{2+}+\mathrm{H}_{2} \mathrm{O} \rightarrow \mathrm{Ca}_{10}\left(\mathrm{PO}_{4}\right)_{6}(\mathrm{OH})_{2}+4 \mathrm{H}^{+} \\
& \mathrm{Al}^{3+}+3 \mathrm{H}_{2} \mathrm{PO}_{4}^{-} \rightarrow \mathrm{Al}\left(\mathrm{H}_{2} \mathrm{PO}_{4}\right)_{3} \\
& \mathrm{Fe}+3 \mathrm{H}_{2} \mathrm{PO}_{4}^{-} \rightarrow \mathrm{Fe}\left(\mathrm{H}_{2} \mathrm{PO}_{4}\right)_{3}
\end{aligned}
$$

Fig. 4 shows that $\mathrm{Ca}_{10}-\mathrm{P}, \mathrm{Ca}_{8}-\mathrm{P}, \mathrm{Ca}_{2}-\mathrm{P}, \mathrm{Fe}-\mathrm{P}$ and $\mathrm{Al}-\mathrm{P}$ precipitates occurred in the process of phosphate adsorption by GSS. The presence of these products indicated that chemical precipitation was the main mechanism of phosphates removal by GSS. The phosphorus removal using untreated GSS by chemical precipitation was only $1.08 \mathrm{mg} / \mathrm{g}$.

The ligand exchange of GSS mainly depended on that the positive charge on the surface of GSS weakened the interaction between proton $(\mathrm{H})$ and oxygen, so the hydroxyl radicals were relatively easy to release [20]. These hydroxyl radicals led to the hydroxylation on the surface. When the Si-O bond and Al-O bond of the silicon oxide tetrahedron and alumina tetrahedron on the GSS surface were cut off, the ligand $\mathrm{OH}$ would bind to the tetrahedron. [22].

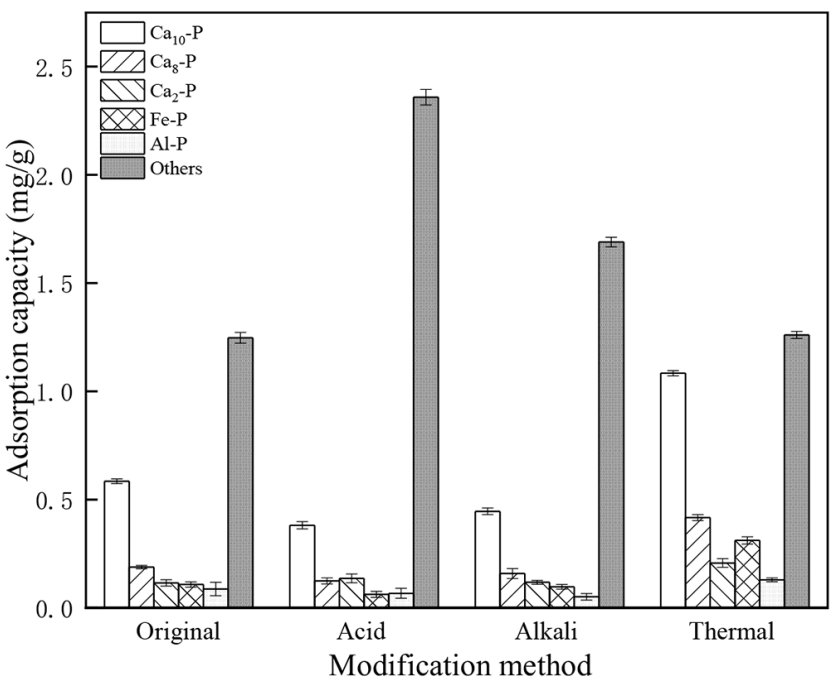

Fig. 4. Phosphates adsorption by GSS. 

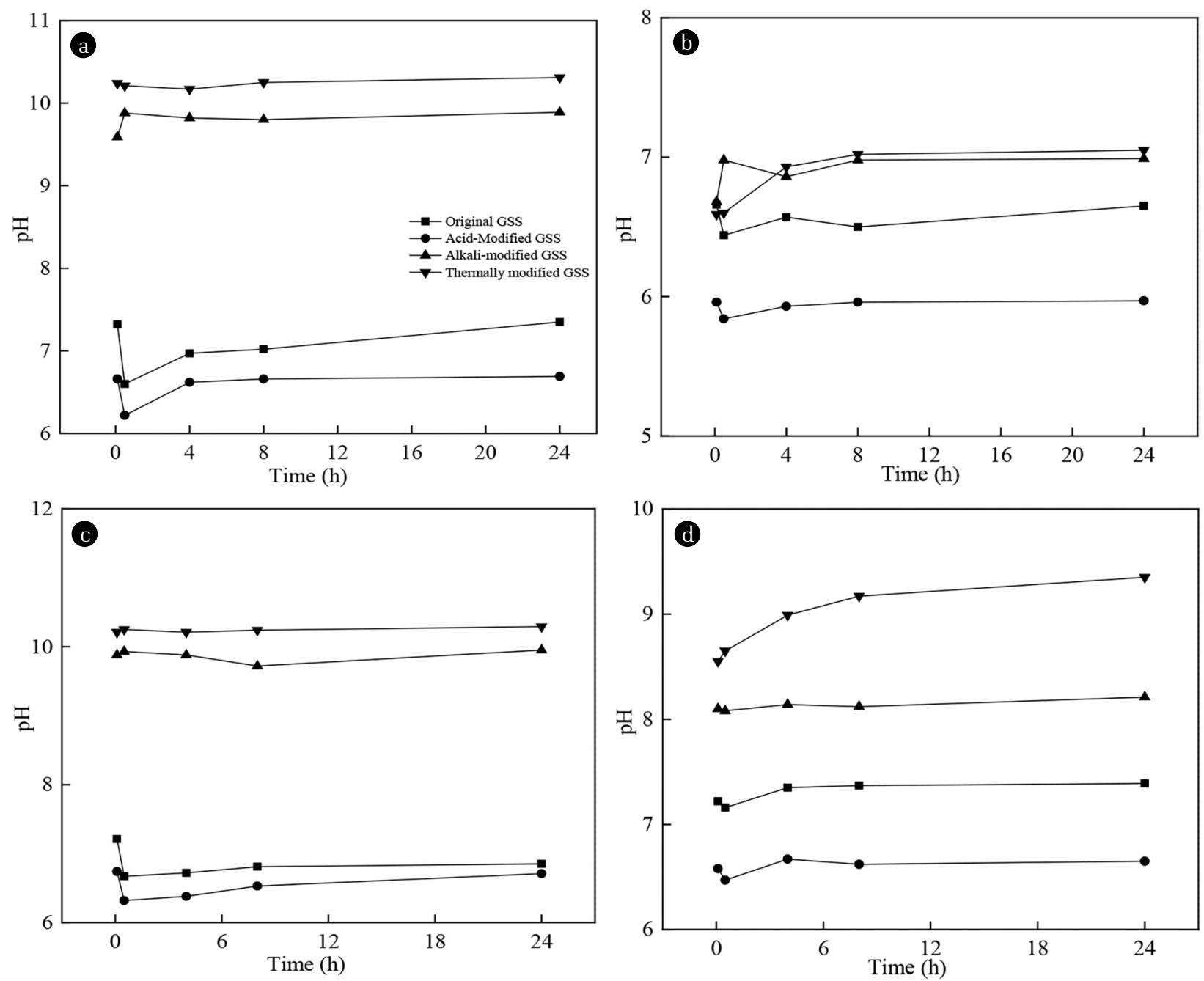

Fig. 5. The change of $\mathrm{pH}$ in adsorption process. (a) In deionized water; (b) In phosphates; solution (c) In nitrates solution; (d) In ammonia solution.

Phosphates could be removed by exchanging with the hydroxyl groups. The equations are as follows:

$$
\begin{aligned}
& 2 \equiv \mathrm{Si}-\mathrm{OH}+\mathrm{H}_{2} \mathrm{PO}_{4}^{-} \Leftrightarrow(\equiv \mathrm{Si})_{2} \mathrm{PO}_{4}+\mathrm{H}_{2} \mathrm{O}+\mathrm{OH}^{-} \\
& 2 \equiv \mathrm{Al}-\mathrm{OH}+\mathrm{H}_{2} \mathrm{PO}_{4}^{-} \Leftrightarrow(\equiv \mathrm{Al})_{2} \mathrm{PO}_{4}+\mathrm{H}_{2} \mathrm{O}+\mathrm{OH}^{-}
\end{aligned}
$$

As shown in Fig. 5 the $\mathrm{pH}$ value of the solution did not change during the process of phosphates adsorption by the modified GSS, that is to say, there was not large amount of hydroxyl groups released, indicating that the coordination exchange was not the mechanism of phosphates adsorption by the GSS.

The adsorption amount of the acid-modified GSS increased with the increase of the acid concentration, the phosphorus removal effect of $5 \mathrm{~mol} / \mathrm{L} \mathrm{HCl}$ for modifying GSS reached $5.12 \mathrm{mg} / \mathrm{g}$ (Fig. 3). But the phosphorus removal ability of acid-modified GSS by precipitation decreased (Fig. 4), it showed that apart from chemical precipitation, GSS could remove phosphorus by other means. The solution containing the acid-modified GSS had lower pH (Fig. 5) and fewer free hydroxyl groups, and the free hydroxyl groups were too few to bind to the metal oxides, which demonstrate acid-modified GSS did not remove phosphates by the ligand exchange. Therefore, phosphates adsorption by acid-modified GSS mainly depends on electrostatic interaction and intermolecular interaction. The surface of GSS was protonated by acid modification, and protonated surface enhanced the ability of GSS to adsorb anions [36]. The improvement of the phosphate adsorption capacity of the acid-modified GSS was attributed to the electrostatic attraction and intermolecular force. However, high concentration of acid made the structure of GSS fragile and unstable (Fig. 2), thus $1 \mathrm{~mol} / \mathrm{L} \mathrm{HCl}$ for modifying GSS was the appropriate acid concentration, and the largest adsorption capacity was $3.22 \mathrm{mg} / \mathrm{g}$.

The alkali-modified GSS had a slightly higher adsorption capacity for phosphates than that of the original GSS. The phosphorus removal effect of 2-4 mol/L NaOH for modifying GSS kept around $2.53 \mathrm{mg} / \mathrm{g}$ (Fig. 3). The effect of phosphorus removal by precipitation of alkali modified GSS (0.87 mg/g) was slightly higher than that of acid modified $(0.77 \mathrm{mg} / \mathrm{g})$, but still lower than that of untreated 
GSS (Fig. 4). In the process of modification, the metal oxides on GSS surface reacted with $\mathrm{NaOH}$, which would cause dissolution and precipitation of metal oxides. After washed with deionized water, the dissolvable $\mathrm{Ca}^{2+}$ concentration was greatly reduced [19]. When the molar ratio of $\mathrm{Ca}^{2+}$ to phosphates in solution was less than 1.67, the precipitation reaction was limited [9], so the precipitation ability of alkali-modified GSS decreased slightly. Similar to acid-modified GSS, alkali-modified GSS still did not release a lot of hydroxyl groups, indicating that the coordination exchange was not the mechanism of phosphates adsorption by the alkali-modified GSS.

The alkali solution with proper concentration can dredged the pores of GSS and increased its specific surface area [32]. The excessive concentration of the alkali solution also destroyed the pore structure of GSS. The improvement of the phosphate adsorption capacity of the alkali-modified GSS was attributed to the electrostatic attraction and intermolecular force. Therefore, the highest adsorption amount of the alkali-modified GSS was obtained by using $3 \mathrm{~mol} / \mathrm{L} \mathrm{NaOH}$ modification.

The thermally modified GSS was similar to the acid-modified GSS. With the increase of the temperature, the adsorption amount was significantly increased; the phosphorus removal effect of 100 $0^{\circ} \mathrm{C}$ modifying GSS reached $3.85 \mathrm{mg} / \mathrm{g}$ (Fig. 3). Thermally modification could improve the chemical precipitation ability of GSS for phosphates (Fig. 4). The amount of phosphorus removal by chemical precipitation of thermally modified GSS was $2.15 \mathrm{mg} / \mathrm{g}$, twice that of untreated GSS. According to XRD spectrums (Fig. 1), the new peaks of thermally modified GSS indicated that $\mathrm{Ca}_{2} \mathrm{Fe}_{9} \mathrm{O}_{13}, \mathrm{CaFe}_{4} \mathrm{O}_{7}, \mathrm{CaSiO}_{3}$, and other substances appeared on the surface of GSS. When GSS entered the solution, $\mathrm{Ca}_{2} \mathrm{Fe}_{9} \mathrm{O}_{13}$, $\mathrm{CaFe}_{4} \mathrm{O}_{7}$, and other substances were easier to hydrolyze $\mathrm{Ca}^{2+}$, which increased the concentration of $\mathrm{Ca}^{2+}$ in solution and made the precipitation reaction move in a positive direction. Thermally modified GSS had the highest $\mathrm{pH}$ value in deionized water (Fig. 5), indicating that there were a large number of free hydroxyl groups in the solution, due to the complex reaction of $\mathrm{Ca}^{2+}$ and $\mathrm{Mg}^{2+}$ with water $[17,30]$. However, the $\mathrm{pH}$ did not change significantly in phosphates solution, either. The thermal modification destroyed the tetrahedral structure of silica and produced $\mathrm{CaSiO}_{3}$, which prevented the free hydroxyl from binding to Si-O on the surface of GSS. Therefore, there was no coordination exchange reaction.

The mass loss of GSS by the thermally modified GSS was small (Table S2). However, the extremely temperature could destroy the structure of GSS, and make GSS loose, brittle and aperture closure. The adsorption effect of the thermally modified GSS had little relation with the specific surface area, so phosphates adsorption by thermally modified GSS could not be electrostatic interaction and intermolecular interaction. Therefore, the phosphorus removal of thermally modified GSS mainly depended on chemical precipitation. The appropriate temperature for thermal modification was $800^{\circ} \mathrm{C}$, with the adsorption capacity of $3.41 \mathrm{mg} / \mathrm{g}$.

Adsorption isotherms were often used to describe the interaction between the adsorbent molecules and adsorbent surfaces [33]. The fitting results of the isothermal adsorption model were shown in Table S3. Langmuir model was more suitable for the adsorption process of phosphates by the GSS, which indicated that the single layer adsorption occurred at a specifically uniform location [30].
The saturated adsorption capacity calculated by the Langmuir model showed that the adsorption capacity of the modified GSS for phosphates followed the order of thermally modified GSS > acid-modified GSS > alkali-modified GSS > original GSS.

\subsubsection{Adsorption effect and mechanism of nitrates}

GSS dia not contain any substance which could precipitate with nitrates, and the untreated GSS had a nitrates adsorption capacity of $2.107 \mathrm{mg} / \mathrm{g}$. Besides chemical precipitation, the mechanisms of nitrate removal by GSS were similar to that of phosphate removal. The adsorption mechanisms of nitrates by GSS included coordination exchange, hydrogen bond, electrostatic interaction and intermolecular interaction force [19, 34]. Metal ions such as calcium, iron and their metal oxides were hydrated on the surface of GSS to form the hydroxides and hydrated metal oxides, so that there were a large number of hydroxyl groups in a mutually associative or separate form present at the interface of the adsorbent. Thus, the nitrates could be adsorbed by ion exchange (Eq. (10)), or through hydrogen bonding (Eq. (11)) with the hydroxyl group.

$$
\begin{aligned}
& \mathrm{M}-\mathrm{OH}+\mathrm{NO}_{3}^{-}=\mathrm{M}^{-\mathrm{NO}_{3}^{-}}+\mathrm{OH}^{-} \\
& \mathrm{M}-\mathrm{OH}+\mathrm{NO}_{3}^{-}=\mathrm{M} / \mathrm{Si}-\mathrm{OH} \cdot \cdots \cdot \mathrm{NO}_{3}^{-}
\end{aligned}
$$

where $\mathrm{M}$ represents $\mathrm{Al}, \mathrm{Fe}$, and $\mathrm{Ca}$.

The acid-modified GSS had the strongest ability for adsorbing nitrates, the adsorption capacity was $3.97 \mathrm{mg} / \mathrm{g}$ when the acid modification condition was $5 \mathrm{~mol} / \mathrm{L}$, higher than that of the original GSS. The $\mathrm{pH}$ of nitrates solution did not change with the decrease of nitrates concentration (Fig. 5). Therefore, the coordination exchange was not the method of nitrates removal by the modified GSS. Due to the few hydroxide and hydrated metal oxide in solution, the hydrogen bond was not the adsorption mechanism. The surface protonation of the acid-modified GSS increased the surface positive charge density. The increased positive charge attracted more nitrates by the electrostatic attraction [36]. The enhancement of nitrates adsorption capacity by the acid-modified GSS was probably due to the electrostatic attraction.

The Si-O-Si bond and Al-O-Al bond on the surface of GSS could produce the dipole-dipole bond adsorption (Vander Waals force) with nitrates, which was greatly influenced by the surface area and void fraction of GSS [20]. The $1 \mathrm{~mol} / \mathrm{L} \mathrm{HCl}$ for modifying GSS had the highest specific surface area and porosity (1.6439 $\mathrm{m}^{2} / \mathrm{g}$ ), and the specific surface area of the modified GSS was positively correlated with its adsorption capacity for nitrates. Considering the mass loss of acid modification, according to the adsorption ratio of unit mass, the optimal modification condition was $1 \mathrm{~mol} / \mathrm{L} \mathrm{HCl}$.

The number of nitrates adsorbed by the alkali-modified GSS was also increased, and when alkali-modification condition was 2-4 $\mathrm{mol} / \mathrm{L} \mathrm{NaOH}$, the adsorption capacity of GSS to nitrates was about $3.06 \mathrm{mg} / \mathrm{g}$ (Fig. 3). Similar to acid modification, alkali-modified GSS did not change the $\mathrm{pH}$ value of the nitrate solution (Fig. 5), so the coordination exchange was not the method of nitrates removal by the modified GSS. The $\mathrm{pH}$ value of nitrate solution adsorbed by alkali-modified GSS was 10.25 , because the surface of alkali-modified GSS was surrounded by the negative charges and the 
electrostatic attraction was weak. After alkali modification, the specific surface area of alkali-modified GSS was slightly higher $\left(0.75 \mathrm{~m}^{2} / \mathrm{g}\right)$ than that of untreated GSS $\left(0.47 \mathrm{~m}^{2} / \mathrm{g}\right)$. Therefore, the ability of GSS to adsorb nitrates was accomplished by the intermolecular force, and the optimum $\mathrm{NaOH}$ concentration was $3 \mathrm{~mol} / \mathrm{L}$.

The thermally modified GSS was poor in adsorption capacity for nitrates, the best adsorption capacity of thermally modification was $1.43 \mathrm{mg} / \mathrm{g}$, which was lower than that of the original GSS (Fig. 3). The influence of thermally modified GSS on the $\mathrm{pH}$ value of solution was investigated (Fig. 5). It was found that the adsorption mechanism was not caused by electrostatic adsorption. The $\mathrm{pH}$ value of nitrate solution adsorbed by thermal modified GSS was 9.95, so the thermally modified GSS had lower electrostatic adsorption capacity. The specific surface area of the thermally modified GSS was the lowest, so its adsorption capacity was the lowest.

The adsorption isotherm models of the modified GSS for nitrates conformed to be Langmuir model, which indicated that the adsorption of nitrates by the modified GSS was mainly monolayer adsorption [19].

\subsubsection{Adsorption effect and mechanism of ammonia}

The ion exchange and physical adsorption were the main mechanisms of ammonia removal [35, 36]. The ion exchange occurred between the metal ions of the GSS surface and ammonia. The ammonia adsorption capacity of the untreated GSS was $1.44 \mathrm{mg} / \mathrm{g}$, and the maximum adsorption capacity of the acid-modified GSS and alkali-modified GSS was $0.44 \mathrm{mg} / \mathrm{g}$ and $0.96 \mathrm{mg} / \mathrm{g}$ (Fig. 3), respectively. The thermally modified GSS had the strongest adsorption capacity (3.93 mg/g). In the ammonia solution, except for $\mathrm{Ca}^{2+}$, the concentrations of other metal ions were lower than $0.01 \mathrm{mg} / \mathrm{L}$, and as seen from Fig. S2, in the process of ammonia adsorption, only $\mathrm{Ca}^{2+}$ concentration treated by the thermally modified GSS increased with time, indicating the mechanism of ammonia removal by the thermally modified GSS was the ion exchange with $\mathrm{Ca}^{2+}$. The concentration of $\mathrm{Ca}^{2+}$ in ammonia solution remained unchanged which treated by the acid-modified GSS and alkali-modified GSS. So, the intermolecular force was the reason for the removal of ammonia by the acid-modified GSS [37, 38]. After

Table 1. Effect of Coexisting lons on Phosphates Adsorption

\begin{tabular}{lccc}
\hline $\begin{array}{l}\text { Types of } \\
\text { solution }\end{array}$ & $\begin{array}{c}\text { Modification } \\
\text { method }\end{array}$ & $\begin{array}{c}\text { phosphates } \\
\text { (mg/g) }\end{array}$ & $\begin{array}{c}\text { nitrates } \\
\text { (mg/g) }\end{array}$ \\
\hline \multirow{2}{*}{$\begin{array}{l}\text { Phosphates } \\
\text { and nitrates }\end{array}$} & Acid & $2.06(68.67 \%)$ & $2.19(67.53 \%)$ \\
& Alkali & $1.95(72.39 \%)$ & $1.62(70.34 \%)$ \\
\hline \hline Types of & Modification & phosphates & ammonia \\
solution & method & (mg/g) & (mg/g) \\
\hline & Original & $1.87(81.04 \%)$ & $0.67(70.68 \%)$ \\
Ph o s ph a te s & Acid & $2.43(81.07 \%)$ & $0.43(86.80 \%)$ \\
and ammonia & Alkali & $2.14(79.44 \%)$ & $1.56(79.77 \%)$ \\
& Thermal & $3.44(106.60 \%)$ & $3.16(103.61 \%)$ \\
\hline
\end{tabular}

Note: The values in brackets are the ratio of the amount of pollutants adsorbed in mixed solution to that in a single solution. the acid modification, some hydrogen ions remained on the GSS surface, and the electrostatic repulsion of ammonia on the surface of GSS increased with the positive charge, which was the reason for the lowest ammonia adsorption capacity of the acid-modified GSS.

\subsubsection{Adsorption test of mixed solution}

The effect of nitrates and ammonia on phosphates adsorption by GSS was shown in Table 1. The concentration of each substance in the mixed solution was $100 \mathrm{mg} / \mathrm{L}$. When nitrate and phosphate coexist in the solution, the adsorption capacity of untreated GSS to the two substances was $12.89 \%$ and $27.61 \%$ lower than that of single solution, respectively. The adsorption capacity of acid modified GSS and alkali modified GSS to these two substances was further reduced. The adsorption capacity of acid modified GSS was $31.33 \%$ and $32.47 \%$ lower than that of single substance, while that of alkali modified GSS was $27.61 \%$ and $29.66 \%$ lower than that of single substance. However, nitrate has little effect on the adsorption capacity of GSS on phosphate. As explained above that GSS adsorbed phosphate mainly by chemical precipitation, electrostatic interaction and intermolecular force, while removing nitrates by electrostatic interaction and intermolecular force. When nitrates and phosphates exist simultaneously, they compete for the active sites and cations on the surface of GSS. The more the adsorption of phosphate by GSS depends on electrostatic interaction and intermolecular force, the more serious the competition will be. The mechanism of phosphate removal by thermally modified GSS was mainly chemical precipitation, so it was less affected.

Compared with nitrates, ammonia had less effect on phosphates. The adsorption mechanisms of ammonia by GSS were ion exchange and intermolecular force. When ammonia and phosphates coexist, ammonia would compete with phosphate for the active sites on the surface of GSS, but ammonia could exchange with metal ions on the surface of GSS to promote the precipitation reaction of phosphate. Thermally modified GSS adsorbed phosphate mainly by chemical precipitation, so ammonia could slightly increase its phosphate adsorption capacity. Acid-modified GSS and alkali-modified GSS depended more on the intermolecular force, so ammonia would still inhibit their ability to adsorb phosphates.

\subsection{Adsorption Effect of Conventional Pollutants in Domestic Wastewater}

The adsorptive capacity of modified GSS in the presence of various pollutants was measured by the domestic wastewater. The pollutants removal rates of GSS before and after modification were shown in Fig. 6. Polyphosphates in the domestic wastewater were generally tripolyphosphate and pyrophosphate. The thermally modified GSS had a good TP removal rate (72.76\%) because of its high removal rate of phosphates and polyphosphates, which could be removed by combining with the metal ions to form the precipitates [39]. The removal rate of TP by alkali modified GSS was $45.52 \%$, which was lower than that by thermally modified GSS. The removal efficiency of TP by acid modified GSS was the lowest and lower than that of untreated GSS.

The removal rates of TN by heat modified GSS and acid modified GSS were $9.67 \%$ and $9.62 \%$ respectively. The thermally modified GSS had the highest removal rate of ammonia and the acid-modified GSS had the highest removal rate of nitrates nitrogen. 


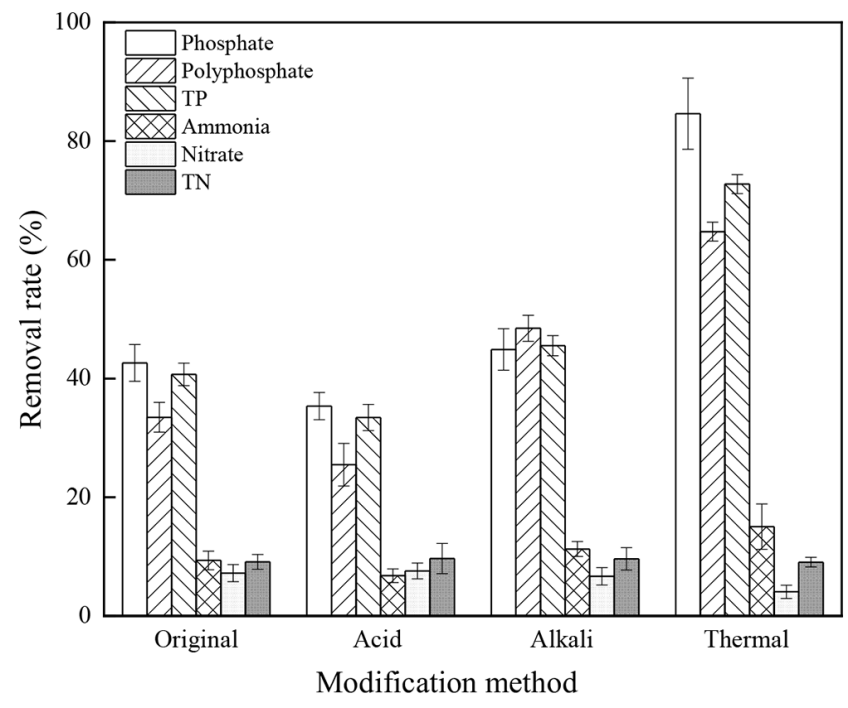

Fig. 6. Removal rate of GSS.

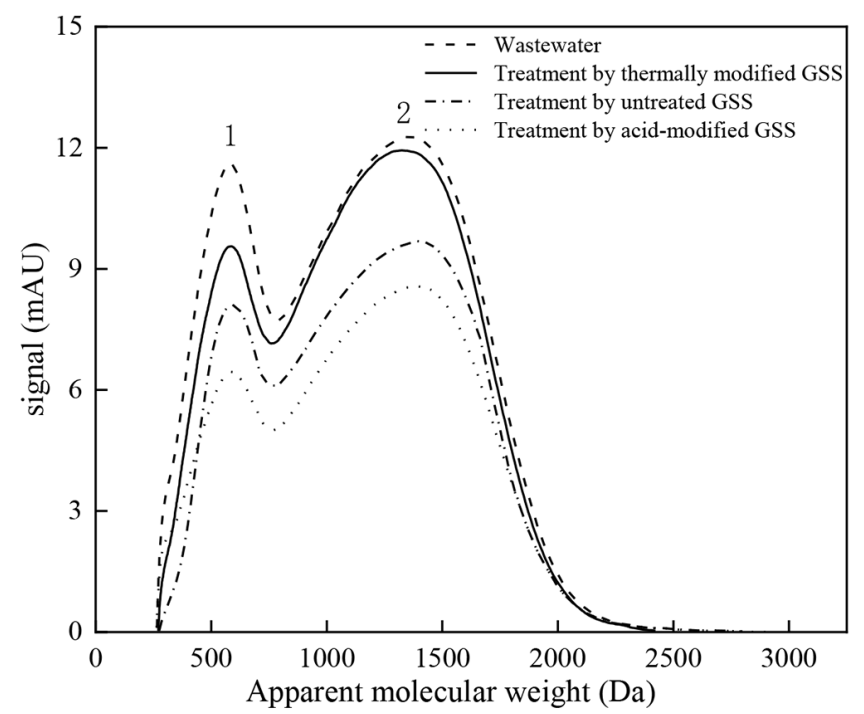

Fig. 7. Molecular weight distributions of wastewater.

The $\mathrm{COD}_{\mathrm{Gr}}$ of the domestic wastewater was $62 \mathrm{mg} / \mathrm{L}$, after adsorption by untreated GSS, acid-modified GSS and thermally modified GSS, the $\mathrm{COD}_{\mathrm{cr}}$ was $55 \mathrm{mg} / \mathrm{L}, 45 \mathrm{mg} / \mathrm{L}$ and $58 \mathrm{mg} / \mathrm{L}$, respectively.

The molecular weight of DOM in wastewater was 150-2800. The main peaks were peak 1 (Da: 580) and peak 1 (Da: 1392) (Fig. 7). The peak 1 and peak 2 of untreated GSS decreased, which indicated that some of the two molecular weight organics were adsorbed by the untreated GSS. The peak 1 of thermally modified GSS changed, the peak 2 remained unchanged, and the two peaks of acid-modified GSS decreased more. This is consistent with the pore size distribution of GSS. The diameter of organic matter with molecular weight less than $5000 \mathrm{Da}$ in wastewater was generally less than $0.85 \mathrm{~nm}$ [25]. After thermal modification and acid modification, the specific surface and pore size of GSS decreased and increased respectively. Thermally modified GSS has no pore on its surface and was mainly adsorbed on its surface, only adsorbed some organic compounds with low molecular weight. The specific surface area of acid-modified GSS, higher than that of untreated GSS, and the pore size was mainly $2-8 \mathrm{~nm}$. Therefore, organic matter could enter the pore of acid-modified GSS, and acid-modified GSS had the strongest adsorption capacity for organic matter [40].

The organic components in domestic wastewater were complex, including humic acid [41], fulvic acid and proteins. Humic acid contained a large number of surface groups, which affected the adsorption process of phosphate by GSS. This process involved many mechanisms, including surface precipitation, complexation reaction and intermolecular force [26]. The existence of other organics in the solution could affect the adsorption of GSS to other pollutants. The low removal rate of TP by acid-modified GSS due to the competition of adsorption sites between DOM and phosphates.

\subsection{Application in Laboratory Subsurface Flow Constructed Wetlands}

The treatment effect of three groups of SFCW on domestic sewage was shown in Fig. S4. After the system runs stably, SFCW had a certain removal effect on COD. G1 had the highest removal efficiency of COD (57.63\%), followed by G2 and G3 (53.01\% and $38.62 \%$, respectively). Filling thermally modified GSS in the SFCW could keep the effluent of TP stable at about $0.4 \mathrm{mg} / \mathrm{L}$, which could overcome the problem that the effluent of sewage treatment plant did not reach the standard. Meanwhile, the SFCW, which filled with thermally modified GSS, also had a good removal effect on TN, and the removal rate of TN was up to $64.4 \%$. The removal of organic matter in wetland was the result of the synergism of physics, chemistry and biology. The modified GSS contained trace elements to promote the growth of plants such as reeds. In addition, the adsorption of TP and TN by the thermally modified GSS increased. Therefore, the use of the thermally modified GSS as filler in SFCW could further promote the removal of organic matter.

\section{Conclusions}

GSS can effectively remove organic matter, phosphates, nitrates, and ammonia from wastewater. After modification, the adsorption capacity of GSS was further improved. The optimum concentration or temperature of the GSS modification was $1 \mathrm{~mol} / \mathrm{L} \mathrm{HCl}, 3 \mathrm{~mol} / \mathrm{L}$ $\mathrm{NaOH}$ or $800^{\circ} \mathrm{C}$. The maximum saturated adsorption capacity for phosphates and ammonia was obtained by the thermally modified GSS, which was mainly through the Ca-P precipitation and the ion exchange between $\mathrm{Ca}^{2+}$ and ammonia. The acid-modified GSS had the highest adsorption capacity for nitrates because it had the strongest electrostatic attraction for nitrates. Nitrates seriously inhibited the removal of phosphates by acid-modified GSS and alkali-modified GSS, and ammonia was helpful to the adsorption of phosphate ${ }^{-}$by thermally modified GSS.

In the domestic wastewater adsorption experiment, the acid-modified GSS had a good removal effect on the organic matter. The thermally modified GSS had the best removal effect on TP and TN. The thermally modified GSS could be added into the constructed wetland as filler to further improve the removal efficiency of COD, TP and TN. The results showed that the modified 
GSS can be used as filler in various equipment, which provided theoretical basis for the practical application of the modified GSS.

\section{Acknowledgment}

This work was supported by National Science and Technology Major Project of China (2017ZX07107-005).

\section{Author Contributions}

S.W. (Ph.D. student) conducted some experiments and wrote the manuscript. S.Y. (M.D. student) conducted most of the experiments. K.D. (Ph.D.), H.C. (Associate Professor) and F.W. (Professor) revised the manuscript. R.Y. (Associate Professor) and B.Z. (Professor) wrote and revised the manuscript.

\section{References}

1. Yu J, Liang W, Li W. Phosphate removal from domestic wastewater using thermally modified steel slag. J. Environ. Sci. 2015;31:81-88

2. Ghosh D, Gopal B. Effect of hydraulic retention time on the treatment of secondary effluent in a subsurface flow constructed wetland. Ecol. Eng. 2010;36:1044-1051.

3. Wang D, Guo F, Wu Y, Li Z, Wu G. Technical, economic and environmental assessment of coagulation/filtration tertiary treatment processes in full-scale wastewater treatment plants. J. Clean Prod. 2018;170:1185-1194.

4. Park T, Ampunan V, Maeng S, Chung E. Application of steel slag coated with sodium hydroxide to enhance precipitation-coagulation for phosphorus removal. Chemosphere 2017;167:91-97.

5. Thompson KA, Shimabuku KK, Kearns JP, Knappe DRU, Summers RS, Cook SM. Environmental Comparison of Biochar and Activated Carbon for Tertiary Wastewater Treatment. Environ. Sci. Technol. 2016;50:11253-11262.

6. Li J, Wu L, Zhou T, Chai X. Preferential removal of phosphorus using modified steel slag and cement combination for its implications in engineering applications. Environ. Technol. Inno. 2018;5:264-274.

7. Han YU, Park SJ, Lee CG, Park JA, Choi NC, Kim SB. Phosphate Removal from Aqueous Solution by Aluminum (Hydr)oxide-coated Sand. Environ. Eng. Res. 2009;14:164-169.

8. Shi Y, Wei N, Wu G. Tertiary denitrification of the secondary effluent in biofilters packed with composite carriers under different carbon to nitrogen ratios. Environ. Eng. Res. 2016;21:311-317.

9. Genz A, Kornmuller A, Jekel M. Advanced phosphorus removal from membrane filtrates by adsorption on activated aluminium oxide and granulated ferric hydroxide. Water Res. 2004;38: 3523-3530.

10. Ali I, Asim M, Khan T. Low cost adsorbents for the removal of organic pollutants from wastewater. J. Environ. Manage 2012;113:170-183.

11. Choi YK, Jang HM, Kan E, Wallace AR, Sun W. Adsorption of phosphate in water on a novel calcium hydroxide-coated dairy manure-derived biochar. Environ. Eng. Res. 2018;24: 434-442.

12. Patil K, Jeong S, Lim H, Byun HS, Han S. Removal of volatile organic compounds from air using activated carbon impregnated cellulose acetate electrospun mats. Environ. Eng. Res. 2018;24:600-607.

13. Singh S, Srivastava VC, Goyal A, Mall ID. Breakthrough modeling of furfural sorption behavior in a bagasse fly ash packed bed. Environ. Eng. Res. 2019;25:104-113.

14. Han C, Wang Z, Yang W, Wu Q, Yang H, Xue X. Effects of $\mathrm{pH}$ on phosphorus removal capacities of basic oxygen furnace slag. Ecol. Eng. 2016;89:1-6.

15. Jha V.K, Kameshima Y, Nakajima A, Okada K. Hazardous ions uptake behavior of thermally activated steel-making slag. $J$. Hazard. Mater. 2004;114:139-144.

16. Liu S; Gao J, Yang Y, Yang Y, Ye Z. Adsorption intrinsic kinetics and isotherms of lead ions on steel slag. J. Hazard. Mater. 2010;173:558-562.

17. Zuo M, Renman G, Gustafsson J, Renman A. Phosphorus removal performance and speciation in virgin and modified argon oxygen decarburisation slag designed for wastewater treatment. Water Res. 2015;87:271-281.

18. Fan Y, Zhang S, Kong J, Miao J. Study on the interaction between an ionic liquid and L-tryptophan by fluorescence spectroscopic technique. Microchem. J. 2011;99:439-442.

19. Yu J, Liang W, Wang L. Phosphate removal from domestic wastewater using thermally modified steel slag. J. Environ. sci. 2015;31:81-88.

20. Yang L, Yang M. Characteristics of nitrate removal from aqueous solution by modified steel slag. Water 2017;9:1-17.

21. Lei X, Xue X. Preparation, characterization and photo catalytic activity of sulfuric acid-modified titanium-bearing blast furnace slag. T. Nonfeer. Metal. Soc. 2010;20:2294-2298.

22. Xue Y, Hou H, Zhu S. Characteristics and mechanisms of phosphate adsorption onto basic oxygen furnace slag. J. Hazard. Mater. 2009;162:973-980.

23. Yu J, Liang W, Wang L, Li F, Zou Y, Wang H. Phosphate removal from domestic wastewater using thermally modified steel slag. J. Environ. Sci. (China) 2015;31:81-88.

24. Yang L, Yang M, Xu P, Zhao X, Bai H, Li H. Characteristics of nitrate removal from aqueous solution by modified steel slag. Water 2017;9:757-774.

25. Press CES. State Environmental protection administration of china, monitoring and analysis methods of water and wastewater [M], Fourthed (in Chinese);Beijing, 2002.

26. Chow CWK, Fabris R, Leeuwen JV. Assessing natural organic matter treatability using high performance size exclusion chromatography. Environ. Sci. Technol. 2008;42:6683-6689.

27. Zuo M, Renman G, Gustafsson JP, Renman A. Phosphorus removal performance and speciation in virgin and modified argon oxygen decarburisation slag designed for wastewater treatment. Water Res. 2015;87:271-281.

28. Xiong J, He Z, Mahmood Q, Liu D, Yang X, Islam E. Phosphate removal from solution using steel slag through magnetic separation. J. Hazard. Mater. 2008;152:211-215.

29. Oguz E. Thermodynamic and kinetic investigations of $\mathrm{PO}_{4}{ }^{3-}$ 
adsorption on blast furnace slag. J. Colloid. Interface. Sci. 2005;281:62-67.

30. Lalley J, Han C, Mohan GR, et al. Phosphate removal using modified Bayoxide E33 adsorption media. Environ. Sci. Water Res. Technol. 2015;1:96-107.

31. Du X, Han Q, Li J, Li H. The behavior of phosphate adsorption and its reactions on the surfaces of $\mathrm{Fe}-\mathrm{Mn}$ oxide adsorbent. J. Taiwan Inst. Chem. Eng. 2017;76:167-175.

32. Masaru O, Junko T, Yasuto N, Mikihiro N, Eiichi K, Masahiko M. Alkali-treatment technique-New method for modification of structural and acid-catalytic properties of ZSM-5 zeolites. Appl. Catal. A. 2001;219:33-43.

33. Kim JH, Park JA, Kang JK et al. Phosphate sorption to quintinite in aqueous solutions: Kinetic, thermodynamic and equilibrium analyses. Environ. Eng. Res. 2015;20:73-78.

34. Mishra P, Patel R. Use of agricultural waste for the removal of nitrate-nitrogen from aqueous medium. J. Environ. Manage. 2009;90:519-522.

35. Hangda D. Adsorption characteristic of modified steel-making slag for simultaneous removal of phosphorus and ammonium nitrogen from aqueous solution. Chin. J. Environ. Eng.
2012;6:201-220.

36. Jha V, Kameshima Y, Nakajima A, Okada K. Hazardous ions uptake behavior of thermally activated steel-making slag. J. Hazard. Mater. 2004;114:139-144.

37. Halim A, Aziz H, Johari M, Ariffin K, Adlan M. Ammoniacal nitrogen and COD removal from semi-aerobic landfill leachate using a composite adsorbent: fixed bed column adsorption performance. J. Hazard. Mater. 2010;175:960-964.

38. Mroziica S, Kurajica S, Vanciinai V, Hodziica E. Ammoniacal nitrogen removal from water by treatment with clays and zeolites. Wat. Res. 2000;34:3675-3681.

39. Wenqi G. A real time in situ ATR-FTIR spectroscopic study of linear phosphate adsorption on titania surfaces. Int. J. Miner. Process. 2001;63:147-165.

40. Sohn JS, Kang HS, Han JH, Yoon YM. Change of molecular weight of organic matters through unit water treatment process and associated chlorination byproducts formation. Environ. Eng. Res. 2007;12:224-230.

41. Kim HC, Lee CG, Han YU, Park SJ, Kim SB, Park JA. Humic acid removal from water by iron-coated sand: A column experiment. Environ. Eng. Res. 2009;14:41-47. 